\title{
STRUCTURAL BREAKS AND THE RELATIONSHIP BETWEEN SOYBEAN AND CORN FUTURES PRICES ON THE DALIAN COMMODITY EXCHANGE OF CHINA
}

\author{
Rufang Wang $^{1}$,Yonghong Du ${ }^{2, *}$,Jian Wang ${ }^{2}$ \\ ${ }^{1}$ School of Economics, Beijing Wuzi University, Beijng, P. R. China 101149 \\ ${ }^{2}$ School of Economics, Nankai University, Tianjing, P. R. China 300071 \\ * Corresponding author, Address: School of Economics, Nankai University, Tianjing, P. R. \\ China 300071, Tel: +86-13910121099, Fax: +86-10-89534320, Email: \\ Yonghongdu@sina.com
}

Abstract: Co-movement between futures prices can arise when commodities are substitutes. Using Johansen's co-integration procedure, we fail to find a significant long-run link between soybean and corn prices on the Dalian Commodity Exchange of China. This relationship is re-examined using Johansen's co-integration procedure that permits structural breaks. Results show evidence of co-integration and hence price discovery. There is a significant break in July 2007 by reason of rare drought in China's main soybean producing areas. The soybean-corn futures market is perfectly integrated, and the soybean price Granger-causes the corn price. Modeling structural breaks in price relationships appears important.

Key words: structural break, co-integration, agricultural commodity futures price, price discovery

\section{INTRODUCTION}

Co-movement between futures prices occurs when two or more prices move together in the long run and the discovery of one price provides valuable information about others. Commonality between commodity futures prices arises particularly when the commodities are substitutes on the

Please use the following format when citing this chapter:

Wang, R., Du, Y. and Wang, J., 2009, in IFIP International Federation for Information Processing, Volume 294, Computer and Computing Technologies in Agriculture II, Volume 2, eds. D. Li, Z. Chunjiang, (Boston: Springer), pp. 919-926. 
supply and/or demand sides, but other reasons include the common impact of changes in macroeconomic variables and speculator behavior (Pindyck et al., 1990).

Malliaris and Urrutia (1996) examine price discovery on the Chicago Board of Trade (CBOT) by using bivariate single-equation models and residual-based tests of co-integration. Using daily data for 1981-1991, they examine long-run linkages between six related agricultural commoditiescorn, wheat, oats, soybean, soybean meal, and soybean oil-where crossprice elasticities of supply and demand are nonzero. The findings show interdependencies between pairwise prices and hence price discovery. Dawson and White (2002) extend this analysis by examining interdependencies between futures prices on the London International Financial Futures Exchange (Euronext.LIFFE) using Johansen's cointegration procedure and daily data for 1991-2000. Findings show no longrun relationships between the prices of barley, cocoa, coffee, sugar, and wheat. The result is particularly surprising because barley and wheat are close substitutes. If futures prices change, processors can hedge prices and change mixes. Dawson, Sanjuán and White (2006) re-examine the long-run relationship between feed barley and feed wheat futures prices on the Euronext.LIFFE using the recent co-integration procedure of Johansen, Mosconi, and Nielsen (2000) where structural breaks are allowed at known points in time and weekly data for 1996-2002. Results show evidence of cointegration and hence price discovery. There is a significant break in October 2000 following Common Agricultural Policy intervention price reductions, the barley-wheat futures market is perfectly integrated, and the barley price Granger-causes the wheat price. Modeling structural breaks in price relationships appears important. The failure to model structural breaks may have led to Dawson and White's counterintuitive conclusion that barley and wheat futures prices are unrelated.

Our aim is to examine the long-run relationship between soybean and corn futures prices on the Dalian Commodity Exchange and hence price discovery, using daily data from 1 July 2005 to 20 June 2008. The price discovery hypothesis is tested here using Johansen's co-integration procedure without breaks and the Johansen's co-integration procedure where structural breaks are allowed at known points in time. The breaks are identified from Perron's unit root test. Perfect price integration is tested where a given percentage change in one price is mirrored in the other; weak exogeneity tests examine Granger-causality; and impulse response functions explore dynamics. 


\section{EMPIRICAL METHOD}

We utilized a vector autoregressive (VAR) model that does not require specifying the causal order prior to estimation

$$
Y_{t}=\mu+\sum_{i=1}^{k} A_{i} Y_{t-i}+\varepsilon_{t}
$$

where $\mathrm{Yt}=[\mathrm{pb}, \mathrm{t} \mathrm{pc}, \mathrm{t}]^{\prime}$ and $\mathrm{pb}, \mathrm{t}$ and $\mathrm{pc}, \mathrm{t}$ are futures prices of soybean and corn in logarithms, $\mu$ and Ai are matrices of parameters, $\mathrm{k}$ is the lag length, and $\varepsilon t$ are error terms. Many price series are nonstationary and regressions between such data are generally spurious. Nonstationarity price series are typically integrated of order one, I(1), and must be first differenced to render them stationary, $\mathrm{I}(0)$. Where two series are $\mathrm{I}(1)$ and move together so that their linear combination is stationary, they are co-integrated, a meaningful long-run equilibrium exists, and the problem of spurious regression does not arise. The Dickey-Fuller test is commonly used to test for unit roots (or nonstationarity) but when a series is subject to a deterministic trend and an exogenous shock causes a structural break, it tends to underreject. Therefore, we follow Perron and test the null of a unit root with a structural break and the alternative is stationarity around a broken level.

If both prices are I(1), the test for co-integration is a test of long-run equilibrium. Johansen's standard test is based on the estimation of the VAR model in (1) transformed into its vector error-correction model (VECM) form. This test is inappropriate however, if structural breaks within the individual series occur, either at different times or at the same time and do not cancel each other out. Johansen, Mosconi, and Nielsen generalize it by admitting up to two predetermined breaks. The sample is divided into $\mathrm{q}$ periods and $j$ denotes each period. The VECM form of (1) where breaks are admitted is

$$
\Delta Y_{t}=\alpha \beta Y_{t-1}+\gamma E_{t}+\sum_{i=1}^{k-1} \Gamma_{i} \Delta Y_{t-i}+\sum_{i=1}^{k} \sum_{j=2}^{q} \kappa_{j, i} D_{j, t-i}+\varepsilon_{t}
$$

Where $\Delta$ is the difference operator; Et is a vector of $\mathrm{q}$ dummy variables $\mathrm{Et}$ $=[\mathrm{E} 1 \mathrm{t} \mathrm{E} 2 \mathrm{t}, \ldots, \mathrm{Eqt}]^{\prime}$ with $\mathrm{Ej}, \mathrm{t}=1(\mathrm{j}=1, \ldots, \mathrm{q})$ if observation $\mathrm{t}$ behind the first observation of the $\mathrm{jth}$ period and zero otherwise; $\mathrm{Dj}, \mathrm{t}-\mathrm{i}(\mathrm{j}=1, \ldots, \mathrm{q}$ and $\mathrm{i}=$ $1, \ldots, \mathrm{k})$ is an impulse dummy that equals unity if observation $t$ is the ith observation of the jth period and are included to facilitate estimation.

The short-run parameters are $\gamma$ of order $(2 \times q)$, $\Gamma i$ of order $(2 \times 2)$ for $i=$ $1, \ldots, \mathrm{k}-1$, and $\mathrm{kj}, \mathrm{i}$ of order $(2 \times 1)$ for $\mathrm{j}=1, \ldots, \mathrm{q}$ and $\mathrm{i}=1, \ldots, \mathrm{k}$. The innovations $\varepsilon \mathrm{t}$ is a $(2 \times 1)$ vector of white noise residuals. The long-run drift parameters are $\alpha=[\alpha b, \alpha c]^{\prime}$ is a vector of adjustment parameters, and $\beta=[\beta b$, $\beta c]$ are the long-run coefficients in the co-integration vector. The co- 
integration hypothesis is formulated by testing the rank (r) of $\pi=\alpha \beta$ by the trace statistic.

Given the co-integration rank, we test two further restrictions on the cointegration space. First, we test that the soybean- corn futures market is perfectly integrated where a $1 \%$ increase in one price leads to a $1 \%$ increase in the other, and the null is

$$
\mathrm{H} 0: \beta b=-\beta c=1
$$

Second, we test for weak exogeneity where the null for pb,t for example is $\mathrm{H} 0: a b=0$.

In the case of $r=1$, a test of weak exogeneity is one of Granger noncausality, and if for example, the nulls that $\alpha b=0$ is rejected and $\alpha c=0$ is not rejected, pb,t Granger-causes pc,t. For each test, the log-likelihood ratio is $\chi_{1}^{2}$.

Finally, impulse response functions (Lütkepohl, 1993) are estimated to explore the dynamics of price adjustment following a shock to each price. Since deviations from the long-run equilibrium are stationary, any shock to the system generates time paths that eventually return to the equilibrium. Each impulse response shows the effect on one price to a shock in the other. When co-integration exists, impulse responses are generally permanent.

\section{DATA AND RESULTS}

Daily rollover nominal closing prices of futures contracts for soybean and corn are used from 1 July 2005 to 20 June 2008, giving 726 observations (Dalian Commodity Exchange). We get missing observations by interpolation. Figure 1 shows that both prices have trended upwards, peaking in March 2008 at $¥ 5495 /$ tonne for soybean and in May 2008 at $¥ 1981 /$ tonne for corn. The minima occurred at $¥ 2370$ /tonne for soybean in augest 2006 , and $¥ 1193 /$ tonne for corn in August 2005. Of particular interest is the trend chang in late 2007.

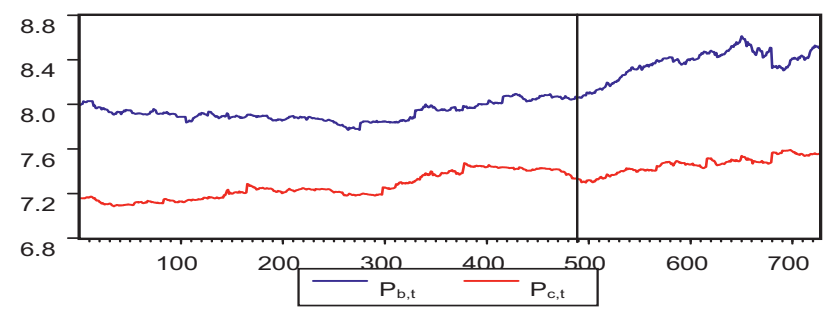

Figure 1. Soybean and corn prices

Following Perron (1997), we examined the nonstationarity and location of a structural break in each price series. The test is performed by estimating 
the breakpoint that minimizes the t-statistic on the parameter associated with the change in intercept. The number of lags, with a maximum of six, is chosen following Said and Dickey's (1984) general-to-specific method where sequential t-statistic on the parameter associated with $\Delta \mathrm{Yt}-\mathrm{i}$ are used at the $10 \%$ significance level. The test statistics are -3.68 for $\mathrm{pb}, \mathrm{t}$ and -3.70 for pc,t (critical value at the $95 \%$ confidence level: -4.84 ). Thus, the null of a unit root is not rejected for both prices and each series is I(1). There is a break in each series, on 13 July, 2007 for pb,t and on 17 May 2007 for pc,t. Because of the U.S. soybean acreage substantially reduced, coupled with China's main soybean producing areas of Heilongjiang historical experience rare drought, the generally upward trend of soybean prices changed sharply in July 2007. Corn acreage substantially increased imposed a reduction in the prices for corn on March, 2007.

Co-integration between $\mathrm{pb}, \mathrm{t}$ and $\mathrm{pc}, \mathrm{t}$ is tested without breaks in Models 1 . In Models 2 implicit in (2), co-integration between pb,t and pc,t is tested allowing for breaks on 17 May, 2007 and on 13 July, 2007. In Models 3, cointegration between $\mathrm{pb}, \mathrm{t}$ and $\mathrm{pc}, \mathrm{t}$ is tested allowing for a single break on 17 May, 2007. In Models 4, co-integration between pb,t and pc,t is tested allowing for a single break on 13 July, 2007. The Akaike Information Criterion (AIC) is used to determine the number of lags and $\mathrm{k}=1$ lags for both models. The trace statistics is used to test for co-integration (table 1). No co-integration vector is found $(r=0)$ in Model 1 and one co-integration vector is found $(\mathrm{r}=1)$ in Model 2 which includes two change in the level. Allowing for a single break, no co-integration vector is found $(r=0)$ in Model 3 and one co-integration vector is found $(r=1)$ in Model 4. Thus, there is the long-run equilibrium relationship between $\mathrm{pb}, \mathrm{t}$ and $\mathrm{pc}, \mathrm{t}$, a single break appears in the vector error-correction model.

Table 1. Co-integration tests (trace statistics)

\begin{tabular}{lcccc}
\hline & Model 1 & Model 2 & Model 3 & Model 4 \\
\hline Breaks & & 13.07 .2007 & 17.05 .2007 & 13.07 .2007 \\
& & 17.05 .2007 & & \\
$\mathrm{H}_{0}: \mathrm{r}=0 ;$ & 5.60 & $15.5^{*}$ & 9.12 & $16.85^{*}$ \\
$\mathrm{H}_{1}: \mathrm{r} \geq 1$ & $(0.74)$ & $(0.05)$ & $(0.35)$ & $(0.03)$ \\
$\mathrm{H}_{0}: \mathrm{r}=1 ;$ & 0.13 & 1.46 & 0.13 & 3.38 \\
$\mathrm{H}_{1}: \mathrm{r} \geq 2$ & $(0.72)$ & $(0.23)$ & $(0.72)$ & $(0.07)$ \\
\hline
\end{tabular}

Notes: 1.The values in parentheses denotes the sgnificance level.

2. *denotes rejection of the hypothesis at the 0.05 level

Hypothesis tests are conducted:

(1) the null that $\beta b=-\beta c=1$ is not rejected ( $\chi_{1}^{2}=1.99$, p-value: 0.16$)$ and the soybean-corn futures market is perfectly integrated; 
(2) the null that $\alpha b=0$ is rejected ( $\chi_{1}^{2}=4.36$, p-value: 0.04 ) while the null that $\alpha \mathrm{c}=0$ is not rejected $\left(\chi_{1}^{2}=2.49\right.$, p-value: 0.11$)$. Thus, pb,t is weakly exogenous, which implies that $\mathrm{pb}, \mathrm{t}$ Granger-causes $\mathrm{pc}, \mathrm{t}$.

Normalizing the co-integrating vector on $\mathrm{pc}, \mathrm{t}$ and imposing the restriction that $\beta b=-\beta c=1$ gives

$$
\mathrm{Pc}, \mathrm{t}=\mathrm{pb}, \mathrm{t}-0.749+\varepsilon \mathrm{t}
$$

the vector error-correction model is

$\Delta \mathrm{pb}, \mathrm{t}=-0.019 \mathrm{ecmt}-0.078 \Delta \mathrm{pb}, \mathrm{t}-1-0.083 \Delta \mathrm{pc}, \mathrm{t}-1-0.001+0.006 \mathrm{Et}$

$-0.009 \mathrm{Dt}-1+0.023 \mathrm{Dt}-2$

$\Delta \mathrm{pc}, \mathrm{t}=-0.0001 \mathrm{ecmt}-0.058 \Delta \mathrm{pb}, \mathrm{t}-1-0.001 \Delta \mathrm{pc}, \mathrm{t}-1+0.0003+0.001 \mathrm{Et}$ -0.009 Dt- $1+0.018$ Dt-2

Where ecmt $=\Delta \mathrm{pb}, \mathrm{t}-1-\Delta \mathrm{pc}, \mathrm{t}-1-0.749$ and the single break is on 13 July, 2007. the $\beta b$ coefficient in an identified co-integrating relationship such as Equation (5) is the ceteris paribus long-run elasticity, and a $1 \%$ increase in $\mathrm{pb}, \mathrm{t}$ leads to a $1 \%$ increase in pc,t. To explore dynamics more fully, (orthogonal) impulse response functions are calculated. These show the impact on one price of a one standard error increase in the other as both adjust back to long-run equilibrium and are illustrated in figure 2 with $90 \%$ confidence intervals. The shock in pc,t has no significant long-run effect on $\mathrm{pb}, \mathrm{t}$, thereby substantiating the corresponding weak exogeneity test. The shock in pb,t leads to a significant and permanent increase of $0.2 \%$ in pc,t in the long run with full adjustment before long-run equilibrium is restored.
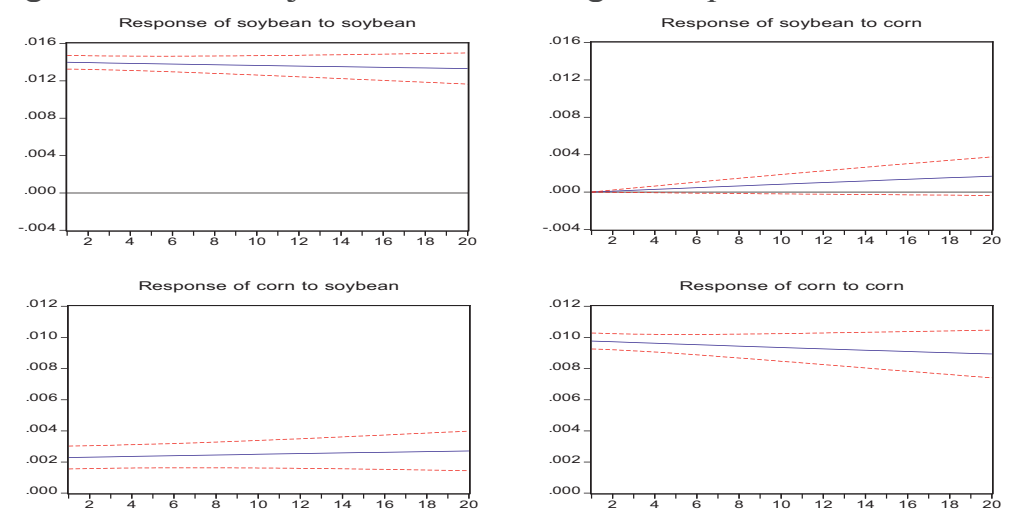

Figure 2. Impulse responses

\section{CONCLUSIONS}

This paper examines the long-run relationship between the futures prices of soybean and corn on the Dalian Commodity Exchange using daily data from 1 July 2005 to 20 June 2008. Unlike previous studies that examine futures price relationships, we used Johansen's co-integration procedure that 
allows for structural breaks at known points in time. The results show evidence of co-integration: a long-run relationship exists between soybean and corn futures prices, and the hypothesis of price discovery is not rejected. This substantiates the results of Malliaris and Urrutia's examination of price discovery on the CBOT for corn, wheat, oats, soybean, soybean meal, and soybean oil.

Using Perron's unit root test, there is a break in each price series: in May 2007 for corn and in July 2007 for soybean. Modeling these two breaks in Johansen's co-integration procedure that permits structural breaks shows that the latter is significant whereas the former is not. The significant break in July, 2007 permanently affected the link between the two prices resulting. Intuitively, there appear to be two explanations for this break in the soybean-corn futures price relationship. Because the U.S. soybean acreage substantially reduced, coupled with China's main soybean producing areas of Heilongjiang historical experience rare drought, domestic and international futures market surged, domestic soybean spot market is also good with the support of many continue to rise significantly. The resulting structural break in the soybean-corn futures price relationship demonstrates the importance of modeling structural breaks. Failure to do so can lead to biased estimates and inappropriate conclusions. Hypothesis tests show that the soybean price is weakly exogenous while the corn price is not. Thus, the soybean price Granger-causes the corn price and not vice versa, and causality is unidirectional. This is perhaps surprising: a priori, we expect bidirectional causality where markets respond to common information about demand and supply. Our results suggest that the soybean futures price incorporates such information while the corn price adjustment follows but not vice versa. There appear to be three explanations. First, soybean is harvested around three weeks before corn and has a price-formation role. Second, soybean and corn are close substitutes where the high protein content favors soybean. Third, the futures market for soybean and corn on the Dalian Commodity Exchange is inefficient because information is not incorporated rapidly into either price due to thin markets, limited speculative involvement, or a relatively small number of traders or small volumes. The implication for traders, that the soybean price Granger-causes the corn price, is that price discovery exists on the Dalian Commodity Exchange of China, and since one price may be used to predict another, consistent profits can be generated. Estimates of long-run coefficients in the co-integrating vector imply that the soybean-corn futures market is perfectly integrated and a $1 \%$ increase in the soybean price leads, ceteris paribus, to a $1 \%$ increase in the corn price. Impulse responses show the impacts on one price of a one standard error increase in the other as both adjust back to long-run equilibrium. A shock in the corn price has no significant impact on the soybean price. In contrast, a $1 \%$ shock in the soybean price leads to a significant and permanent $0.2 \%$ 
increase in the corn price. This supports the conclusion that the soybean price is weakly exogenous. The permanent change in the corn price in response to the change in the soybean price may indicate that part of the industry responds to soybean price changes by permanently changing the amount of corn in formulations. We chose to examine the link between soybean and corn futures prices because commonality between commodity futures prices arises particularly when the commodities are substitutes on the supply and/or demand side. Commonality can also arise because of common impacts of changes in macroeconomic variables and speculator behavior. Analysis of these other bivariate relationships, which are not reported, suggests the result here does generalize: there is evidence of co-integration in all relationships when breaks are included, and at least one break is significant in each co-integrating vector. Thus, there is wide price discovery on the Dalian Commodity Exchange. Our findings suggest that it is important to model structural breaks when examining the relationship between futures prices and a failure to do so may lead to the erroneous conclusion that price discovery is absent.

\section{ACKNOWLEDGEMENTS}

Funding for this research was provided by the research funding base of Beijing Wuzi University (P. R. China).

\section{REFERENCES}

Dawson, P.J., Ana I.Sanjuán, and B. White. Structural Breaks and the Relationship between Barley and Wheat Futures Prices on the London International Financial Futures Exchange." J. Review of Agricultural Economics, 2006,28 (12):585-594.

Dawson, P.J., and B. White. "Interdependencies between Agricultural Commodity Futures Prices on the LIFFE.” J. Futures Markets, 2002,22 (6):269-80.

Johansen S., R. Mosconi, and B. Nielsen. "Cointegration Analysis in the Presence of Structural Breaks in the Deterministic Trend," J. Econom., 2000, 3 (12):216-49.

Johansen, S. "Statistical Analysis of Cointegration Vectors." J. Econ. Dyn. Control 12, (June 1988):231-54.

Lütkepohl, H. Introduction to Multiple Time Series Analysis. Berlin: Springer-Verlag, 1993:43-56.

Malliaris, A.G., and J.L. Urrutia. "Linkages between Agricultural Commodity Futures Contracts.” J. Futures Markets, 1996,16 (8):595-609.

Perron, P. "Further Evidence on Breaking Trend Functions in Macroeconomic Variables," J. Econometrics, 1997 ,80(10):355-85.

Pindyck, R.S., and J.J. Rotemberg. "The Excess Co-Movement of Commodity Prices," Econ. J. 1990, 100(12):1173-89.

Said, S.E., and D.A. Dickey. "Testing for Unit Roots in Autoregressive-Moving Average Models of Unknown Order," Biometrika, 1984, 71(12):599-607 